\title{
HABITAR LOS INTERSTICIOS: RETOS A LA INVESTIGACIÓN SOBRE GÉNERO Y JUVENTUD EN CLAVE FEMINISTA
}

\author{
Silvia ELIZALDE ${ }^{1}$ \\ CAROlina Álvarez VALDÉS ${ }^{2}$
}

\begin{abstract}
RESUMEN
En el marco de entrevistas realizadas a investigadoras e investigadores de relevancia en el campo de estudios de las juventudes en América Latina y Europa, conversamos con Silvia Elizalde, repasando su trayectoria intelectual atravesada por el cruce y la tensión permanente entre juventudes, género, clase y generaciones en el contexto argentino. La entrevista comienza repasando el tránsito entre estas claves de comprensión dentro de su propio trabajo, evidenciando las transformaciones en estas perspectivas analíticas en contextos de acelerados cambios y de juventudes en movimiento. Posteriormente, nos detenemos en las reflexiones metodológicas considerando la conversación respetuosa y la responsabilidad en la escritura como maneras de acercamiento desde metodologías feministas. Finalmente, avizora la importancia de la perspectiva generacional para pensar las marcas de la pandemia en las juventudes y la sociedad.
\end{abstract}

PALABRAS ClAVES: GÉNERO, FEMINISMO, JUVENTUDES, GENERACIONES, ARGENTINA

1 Argentina, Doctora en Antropología, Investigadora Independiente del Consejo Nacional de Investigaciones Científicas y Técnicas (CONICET) con sede en el Instituto de Investigaciones de Estudios de Género de la Facultad de Filosofía y Letras UBA. Autora de Tiempo de chicas. Identidad, cultura y poder (Buenos Aires, Grupo Editor Universitario, 2015) y compiladora y autora de Jóvenes en cuestión. Configuraciones de género y sexualidad en la cultura (Buenos Aires, Biblos, 2011), entre otros trabajos científicos. Docente de grado y postgrado en la Universidad de Buenos Aires y la Universidad Nacional de La Plata. Correo electrónico: silvitaelizalde@gmail.com

${ }^{2}$ Doctora (C) en Educación, Universidad Alberto Hurtado-Universidad Diego Portales. Parte del Núcleo de Investigación y Acción en Mundos Juveniles, Departamento Sociología, Facultad de Ciencias Sociales, Universidad de Chile. Correo electrónico: caroalvarezvaldes@gmail.com. ORCID ID: https://orcid.org/0000-0003-0402-5072 


\title{
HABITAR OS INTERSTÍCIOS: DESAFIOS À PESQUISA SOBRE GÊNERO E JUVENTUDE A PARTIR DE UMA PERSPECTIVA FEMINISTA
}

RESUMO

No contexto de entrevistas realizadas a relevantes pesquisadoras e pesquisadores no campo dos estudos das juventudes na América Latina e Europa, conversamos com Silvia Elizalde, revendo sua trajetória intelectual atravessada pelo cruzamento e a tensão permanente entre juventudes, gênero, classe e gerações no contexto argentino. A entrevista começa revendo o trânsito entre estas chaves de compreensão dentro de seu próprio trabalho, evidenciando as transformações nestas perspectivas analíticas em contextos de aceleradas mudanças e de juventudes em movimento. Posteriormente, paramos nas reflexões metodológicas considerando a conversa respeitosa e a responsabilidade na escrita como formas de abordagem a partir das metodologias feministas. Finalmente, observamos a importância da perspectiva geracional para pensar as marcas da pandemia nas juventudes e na sociedade.

PALAVRAS-CHAVE: GÊNERO, FEMINISMO, JUVENTUDES, GERAÇÕES, ARGENTINA

\section{INHABITING THE INTERSTICES: CHALLENGES TO THE RESEARCH ON GENDER AND YOUTH FROM A FEMINIST PERSPECTIVE}

\begin{abstract}
Within the framework of interviews with prominent male and female researchers in the field of youth studies in Latin America and Europe, we had a talk with Silvia Elizalde, reviewing her intellectual trajectory marked by the clash and the permanent tension among youth, gender, class, and generations in the Argentinian context. The interview begins by reviewing the transition of these keys to understanding within her own work, evidencing the transformations in these analytical perspectives in contexts of accelerated changes and youth on the move. Subsequently, we dwell on methodological reflections, considering respectful conversation and responsibility in writing as ways to approach from feminist methodologies. Finally, we look at the importance of the generational perspective in order to think about the traces of the pandemic on youth and society.
\end{abstract}

KEYWORDS: GENDER, FEMINISM, YOUTH, GENERATIONS, ARGENTINA 


\section{INTRODUCCIÓN}

Este es el tercer número de la revista Última Década, con una sección destinada a entrevistas con investigadoras e investigadores de relevancia dentro del campo de estudios de las juventudes. En esta ocasión, la conversación fue con Silvia Elizalde, Investigadora Independiente del CONICET (Argentina) y doctora en Antropología de la Universidad de Buenos Aires, quien ha desarrollado un extenso trabajo en el cruce entre juventudes, género y clase social principalmente en Argentina, pero con implicancias para pensar desde el Sur. El objetivo de esta conversación fue conocer el tránsito biográfico de Silvia en relación con la investigación que ha desarrollado, cuáles han sido sus claves de comprensión, sus transformaciones, y las preguntas investigativas actuales en un contexto de activismos y militancias feministas. Silvia Elizalde ha problematizado las categorías analíticas en uso para estudiar las juventudes considerando siempre el contexto, pero como recalca en esta conversación, no como un telón de fondo, sino que como parte fundamental e indispensable para pensar la siempre compleja relación entre lo micro y lo macro, lo individual y lo colectivo, y entre el género y las juventudes. A lo largo de la entrevista sus palabras nos sacan de los lugares cómodos y de nuestros saberes arraigados, realizando un cuestionamiento a los sentidos comunes y a los conceptos que iluminan tanto, que llegan a tapar los grises e intersticios que es hacia donde dirige su mirada. En esos puntos profundiza por medio de viejas y simples preguntas en tiempos de cambios y redefiniciones, no llegando con las respuestas de antemano y dejándose sorprender e interpelar por les jóvenes. Así también profundizamos en las metodologías y el desarrollo de dos cuestiones en las que solemos detenernos poco - $\mathrm{O}$ no lo suficiente- : la situación de entrevista como una conversación respetuosa, y la responsabilidad en la escritura y en nuestra palabra pública como investigadoras/es de juventudes, como otros modos de acercarse a las juventudes en movimiento. 


\section{EL TRÁNSITO DE LOS CRUCES ENTRE JUVENTUDES, CLASE Y GÉNERO}

CAV: Silvia, revisando dos artículos que son parte de tu producción en Última Década, del año 2006 y 2018. En el artículo «El androcentrismo en los estudios de juventud: efectos ideológicos y aperturas posibles» (Elizalde, 2006) buscabas entender cómo se estaba hablando de los y las jóvenes, cómo se visibilizaban o no a las mujeres jóvenes en el campo de estudios, mientras que en el año 2018 indagas en el cruce entre género y edad, dando cuenta de las operaciones de iluminación y difuminación a partir del caso de María Soledad (Elizalde, 2018). ¿Cómo estos dos trabajos muestran un tránsito en tu propia perspectiva en el campo de estudio de las juventudes y el género?

SE: Efectivamente, en el primer artículo había una inquietud de mi parte por revisar cómo aparecía la diferencia de género en las investigaciones sobre juventudes, en un momento en el que este campo estaba en plena expansión, y diría, que con mucho mayor respaldo y legitimidad institucional, al menos en Argentina. Me refiero a aquellas condiciones de institucionalización de un campo que implican la conformación de grupos de investigación, líneas de financiamiento, articulación entre equipos, y colocación de algunos grupos en la escena regional como interlocutores válidos para hablar de Argentina, el Cono Sur y establecer distintos diálogos. En ese análisis buscaba ver los usos ideológicos o regulatorios que también la academia produce en relación con estas diferencias, lo que tal vez marca una distancia importante con el presente o con los textos más actuales de los últimos años, en los cuales «la problemática de género» se ha instalado completamente en la agenda social, mediática, académica. ¿Y qué significa esto? No que exista una coherencia de significados entre estas esferas ni, mucho menos, al interior del propio campo científico académico local, pero sí que hay una mayor recepción a estos temas, con menores sospechas. Ahora el cruce juventudes y géneros asume a ambos términos en plural. Esto antes no existía y es resultado, no de un efecto 
meramente académico o institucional de las decisiones del campo científico, sino de un cambio social mayor. Siempre pensando que nuestro quehacer y nuestro lugar como intelectuales están inmersos en un contexto en permanente transformación creo que este desplazamiento del investigador, la investigadora en los temas de juventudes y género, del margen al centro en tanto «expertos/as» es un efecto, también, de esta modificación de los escenarios y de las condiciones en las cuales producimos preguntas de investigación. A mí me gusta pensar que nuestro quehacer está indisociablemente ligado a esos cambios societales, pero al mismo tiempo - insisto - somos responsables del lugar que vamos ocupando en términos intelectuales en relación con estos cambios. En América Latina y de modo paradigmático en Argentina, la reemergencia de una agenda amplia de temas de género, de la mano y la propulsión de las nuevas generaciones en la escena pública y política local y regional, necesariamente nos ha modificado como intelectuales, ha modificado las preguntas $\mathrm{y}$, por supuesto, nos ha puesto a pensar sobre las nuevas o mejores formas de abordar estos procesos en la vida de les jóvenes.

CAV: En ese sentido, Silvia, retomando a autoras feministas que parten desde sus propias experiencias y biografías, situándose en el campo de estudio y socialmente, ¿cómo te sitúas tú en la investigación que has desarrollado? Y en términos metodológicos, algo mencionaste respecto a cómo van cambiando y cómo vamos pensando otras metodologías. En tus trabajos abordas temas como el empoderamiento y la liberación sexual con una mirada crítica (Elizalde y Felitti, 2015). En esta comprensión del feminismo y el género como una tensión y una pregunta permanente, ¿cómo vas tomando esta diversidad de corrientes y formas de comprensión? Como tú bien dices, las/los jóvenes nos están interpelando constantemente, incluso nuestro lenguaje, nuestra forma de acercarnos y de ejercer poder también como investigadoras/investigadores.

SE: Empecé trabajando sobre jóvenes en mi tesis de grado «El joven bajo sospecha», muy en la línea de mi formación en comunicación, que en ese 
momento como ciencia social estaba muy adherida a la pregunta por la representación: ¿cómo vuelven a estar presentados por otros discursos los sujetos jóvenes? Quienes aparecían en la escena pública claramente eran los varones, entonces esa primera investigación me interpeló en términos de cómo se articulaba juventud con clase, porque trabajaba con representaciones de jóvenes de sectores populares, quienes básicamente aparecían en el lugar de la amenaza al orden social. Y eso era de alguna manera un valor clásico asociado a la juventud. De hecho, sabemos que la juventud fue inicialmente interrogada por las ciencias sociales, sobre todo, en su carácter disruptivo respecto de un orden, una ley y un cierto sentido de comunidad que la presencia juvenil alteraría. En todas esas representaciones, la juventud aparecía fuertemente masculinizada. Advertir este sesgo de los discursos sobre jóvenes me condujo también a revisar mi propio discurso, porque yo finalmente estaba analizando lo que los otros discursos me traían de la juventud. Ahora bien, la diferencia entre analizar lo que cierto sentido común o cierto momento del statu quo académico trae respecto de les jóvenes es algo muy distinto a hacerse preguntas atravesando esos sentidos comunes. Recién ahí, entonces, pude preguntarme ¿dónde están las chicas? ¿Cuál es la especificidad de género que produce cambiar la pregunta? No cambiar el foco de un sujeto a otro sujeto, sino preguntarse por la relación de aquello que los distingue y al mismo tiempo los ubica en el mapa social de las jerarquías de género. Preguntarse, entonces, por la interpelación que produce el análisis cuando el género se lee articulado a otras diferencias. La discusión que intentaba en esos primeros textos era ¿cómo hacer que el género no operase meramente como esa variable que proponía sobre todo la sociología y que la unificaba a la etnia o a la clase? No porque las volviera intercambiables, sino porque las traía a un mismo frente, como si pudieran ser recortadas del mismo modo cuando, justamente, el desafío en el análisis es advertir cómo estas diferencias, articuladas entre sí, operan todo el tiempo en distintos planos. Esto es: por momentos aparecía la clase como el foco que me permitía entrar a un problema, pero consciente de que la clase no 
actúa sola sino que articula con otras diferencias, se trataba de mirar el juego de luces y sombras que construían esas articulaciones en cada contexto. Esto no existía hasta ese entonces en los estudios de juventud, por lo menos a nivel local, y parecía propicio iniciarlo. Retomando una de tus preguntas, yo me sentí temprana y fuertemente interpelada por los feminismos. Empecé a leer teoría feminista y no podía creer que en el campo de estudios de juventud no apareciera ese corpus de lecturas que tanto me había movilizado. Pero no porque me había movilizado a mí, sino porque no podía entender cómo el feminismo con su impulso transformador, sus preguntas, se había instalado tan tibiamente en un campo que de por sí nació haciéndose preguntas bien interesantes. Por lo menos en nuestros países, los estudios sobre jóvenes permitieron traer mucho aire fresco a ciertas presunciones y cristalizaciones que venían operando de manera naturalizada en las ciencias sociales. Esa fue mi entrada y mi recorrido inicial.

CAV: Vinculado a los contextos y las trayectorias investigativas personales, ¿en qué momento de tu trayectoria comenzaste a realizar este cruce entre clase, juventudes y género? ¿Qué querías indagar? ¿Y cómo se vinculaba con el contexto social?

SE: Por un lado, llegó en términos del tipo de investigación que buscaba producir, que estaba muy vinculado con una mirada interesada en los lugares de fuga, en los lugares de media luz y no necesariamente en aquello que iluminaban completamente los conceptos ya consagrados. Porque mientras ciertos conceptos se presentaban con una potencia tan fuerte que parecían producir un foco total de iluminación - por el grado de legitimidad alcanzado y porque habían permitido, o aún permiten, efectivamente, una comprensión más integral de algunas dinámicas sociales_-, el feminismo se preguntaba por esos lugares de media luz, de hendidura. Por esos intersticios que habilitaban hacerse preguntas «menores», tal vez porque ahí traían otra agenda de temas o focalizaciones: la vida privada, la intimidad, las relaciones intra e intergénero; 
esas articulaciones más microsociológicas con impacto en lo macro. Me parecía que había elementos muy potentes en los textos de teoría feminista que empezaba a leer, pero también tenía que ver con una curiosidad, con no volver a encontrar un poco lo que ya sabíamos desde ciertos sentidos comunes. Siempre rechacé esa posibilidad tan a la mano de que la ciencia viniera a traer el brillo de la erudición para terminar diciendo casi lo mismo que el sentido común, pero más sofisticadamente. Entonces, creo que la diferencia con un análisis social y cultural de les jóvenes más agudo tiene que ver con atravesar esa «comodidad» (entre comillas), con conmoverla respecto del uso de herramientas conocidas y de preguntas trilladas aplicadas al infinito a distintos corpus empíricos. De hecho, en Argentina entre fines de la década del 90 y los primeros años del 2000 se produjeron trabajos muy similares. Por ejemplo, el análisis de representaciones de las chicas en distintas superficies mediáticas las revistas, la publicidad, los diarios_-, que de cierto modo estuvo bien porque ayudó a ampliar el universo de objetos, temas y sobre todo, de perfiles que se animaban a investigar estos cruces. No lo condeno, me parece que forma parte del camino de construcción de un campo. Pero en algún punto hay una especie de cinta de Moebius. Esta cosa de que volvemos a un punto por el cual ya hemos pasado muchas veces, con alguna leve variación. Contra eso creo que construyo mis preguntas, no para encontrar o inventar lo que no existe, sino al contrario, para hacerme nuevas preguntas, pero también para volver a preguntas más sencillas, más estructurales y fundamentales. Me parece crucial tener como base de lo que podemos decir sobre este cruce un enorme entrenamiento en una escucha atenta a los sujetos, a las chicas, a los chicos, ya que ahí aparece la posibilidad de advertir cuánto tiene que moverse el conocimiento científico para poder decir algo significativo sobre lo que está efectivamente ocurriendo, sobre la dinámica vital de los sujetos. Creo que ese es el desafío. 


\section{JUVENTUDES EN MOVIMIENTO: LA CULTURA DEL}

\section{CUARTO, LOS CORTES GENERACIONALES Y LOS LINAJES DE}

\section{LA FEMINIDAD}

CAV: Respecto a lo que apuntas de estudiar estas zonas grises, estos intersticios, si pudieses ahondar un poco más y ejemplificar con alguna de las investigaciones que has desarrollado pensando en estos grises o intersticios y la vuelta a estas preguntas más simples a las que apuntabas.

SE: Comencé en mi tesis doctoral, y continué durante varios años, trabajando sobre chicas de sectores populares. Ahí aparecía muy fuerte la articulación con la clase, con sus posibilidades o imposibilidades, en un momento donde la figura del joven disruptivo era la del pibe chorro, muy abordada por la sociología argentina. Una figura que delineaba un perfil de sujeto producto de la matriz cultural del neoliberalismo y del repliegue del Estado, de profunda crisis económica, y donde podían leerse tanto las ansiedades sociales como la respuesta de esos pibes a esas regulaciones tan fuertemente articuladas en torno a la clase, el género masculino y la edad. Entonces, por un lado, empecé preguntándome por el lado B de esa configuración, ¿qué pasaba con las chicas? Porque en los barrios donde estaban esos pibes chorros había pibas, entonces, ¿qué pasaba ahí? Consideré toda la discusión dada por Angela McRobbie, que para mí fue una autora muy central en mis primeros años como investigadora, donde abordaba la noción de «la cultura del cuarto». Esto es, todo lo que ocurre en esa habitación donde las chicas se reúnen a hablar, maquillarse, probarse ropa, aquí también a tomar mate, y todo lo que significa el cuarto propio para esas pibas de sectores populares en una casa donde viven ocho, donde los metros cuadrados no dan para tener mucha comodidad ni autonomía, y donde son efectivamente muy controladas. Sin embargo, todo esto ocurría en los 2000, cuando la trama social en Argentina estaba estallada, precisamente, por el impacto del neoliberalismo más feroz de la década precedente, que producía esto y que tanto costó y cuesta reparar. Entonces, luego de focalizar en las 
chicas de sectores populares en el cruce entre clase, género y edad, sumé otras dimensiones y prácticas cruciales. Me di cuenta de que las chicas que había analizado tenían un uso bastante lúdico y al mismo tiempo politizado de algunos elementos de producción cultural, por ejemplo, de la fotografía y del modo en que salían al barrio a fotografiar. Habían formado parte de un taller de fotografía social. Entonces registré también cómo la fotografía les permitía decir otras cosas, construir otras narrativas que no tenían como soporte la palabra, pero que tenían la impronta de la mirada que ellas producían sobre sí mismas y les otres. Ahí se me despertó aún más la curiosidad por aunar los estudios de juventud con el feminismo, porque el feminismo trae una propuesta de proyecto cultural, de cambio de esa matriz absolutamente rígida que pone a los sujetos en una grilla preestablecida y que conspira a favor de su reproducción naturalizada, y esa perspectiva podía iluminar mis registros. Entonces, ¿dónde aparece la posibilidad de ese proyecto emancipador del feminismo? ¿Cómo se puede pensar esto encarnado en la vida de las mujeres jóvenes? A partir de estas preguntas pasé a hacer otros trabajos de investigación, que fueron menores en su aliento; fueron investigaciones más puntuales, más como esas investigaciones que hacemos a término, ya no vinculadas a un requisito de la academia. Fueron indagaciones que hice como parte de un recorrido que tuve que atravesar para ampliar las evidencias y ajustar la lente analítica. Trabajé, por ejemplo, con chicas de clase media que buscaban en el alternativismo cultural, formas de contestación a las regulaciones de género y sexualidad de las cuales eran objeto. Para ello, entrevisté a chicas que diseñaban su propia ropa y que habían empezado a elaborar un discurso totalmente sui generis sobre el concepto de belleza o la autonomía del cuerpo en tiempos donde el feminismo no había llegado todavía a sus vidas. El hacer ropa era una forma cultural, una práctica performática respecto de lo que podían decir de su propio género y de la relación con les otres. Se advertía ahí un posicionamiento claro sobre el arreglo corporal, sobre el mandato de la belleza y esos eran lugares de fuga, esas zonas grises de las 
que hablé antes: las pequeñas transformaciones de la propia vida, que vistas de manera sistemática me permitían ver que esas chicas estaban haciendo una diferencia muy importante en relación con lo que habían hecho sus propias madres sobre asuntos claves asociados al género y la sexualidad.

CAV: ¿Cómo aparecen en ese proceso las relaciones generacionales y la construcción de feminidad?

SE: Para mí siempre fue muy importante la relación entre las cohortes generacionales y los linajes de la feminidad, que construyen una suerte de legado que se transfiere, y a la vez, un conjunto de disposiciones y posibilidades abiertas a la reapropiación y resignificación por parte de las nuevas generaciones de mujeres. Cómo han sido educadas esas madres, cuál ha sido la pedagogía sentimental que recibieron, las marcas de género que las han puesto en determinados lugares y no en otros, los destinos que construyen esas dinámicas de género para sí mismas y para su descendencia. Lo que aparecía en mis entrevistadas era una narrativa distinta respecto de las experiencias de socialización de género de sus madres, que en muchos casos eran madres muy jóvenes, por lo que bien podrían haber participado de vivencias generacionales similares. Para mediados de los 2000 empezaba a advertir que ahí había otro espacio de fuga bien interesante. Luego, también trabajé en otra investigación puntual sobre diversidades sexuales (lesbianas e identidades no binarias), donde abordé algo de lo que luego sería una nueva y más reciente investigación en torno de las formas de sexo-afectividad. Veía ahí cómo se tramaban las relaciones amorosas y eróticas entre chicas, que también eran relaciones de cooperación para otro tipo de prácticas culturales como el armado de talleres, de círculos, donde fuera posible encontrarse con otras jóvenes que querían de alguna manera poder desplegar más libremente su identidad sexual. Y esto iba ya de la mano de una creciente organización de los activismos de género y sexualidad en la sociedad civil argentina. Pensemos que los 2000 son años de resurgimiento de muchas organizaciones militantes en torno al género y la 
sexualidad y las chicas empezaban a encontrar en esas formas de articulación maneras de pensarse, habitarse, con un discurso yo diría más bien de género y no tanto estrictamente feminista.

CAV: ¿Cómo esto fue incidiendo en ti y en otras investigadoras?

SE: Bueno, estas investigaciones más exploratorias me permitieron ir saliéndome del camino más previsible. $Y$ ver cómo el género empezaba a tener una resonancia emancipatoria en la vida de muchas chicas, pero de ninguna manera de modo inexorable ni absolutamente completo. Aclaro que cuando pienso estos ecos, estas resonancias emancipadoras, es siempre en el marco de pensar las dinámicas sociales de manera conflictiva, teniendo en cuenta las tensiones, en las articulaciones complejas entre los contextos, las prácticas de los sujetos, las condiciones de posibilidad y las eventuales formas de antagonismo. Vislumbrar ahí qué traían esos posicionamientos sexo-genéricos de las chicas me iluminó con respecto a un montón de temas sobre los cuales no encontraba casi literatura local. Me volví una lectora muy voraz de la literatura de los estudios de género y la teoría feminista que traían las latinoamericanas, pero también las anglosajonas, las francesas, además de que encontré un conjunto de compañeras de ruta que son las investigadoras de estudios de género y feministas brillantes y potentes que hay en mi país: historiadoras, antropólogas, especialistas en comunicación o en literatura. Hace 25 años que formo parte de un instituto de estudios de género, perteneciente a la Facultad de Filosofía y Letras de la UBA, y fue allí que encontré también un lugar donde alojar mis inquietudes. 


\section{LA RECONFIGURACIÓN DE LA INTIMIDAD Y EL AMOR EN TIEMPOS DE ACTIVISMOS FEMINISTAS}

CAV: Silvia, es muy interesante esta idea del linaje de la feminidad y de la pedagogía sentimental. A propósito, recordé toda la línea de estudios generacionales en juventudes respecto a las formas creativas, problematizadores y transformadoras en que las nuevas generaciones pueden tomar esta «herencia»y el contexto en el que se desenvuelven. Entonces, cuando investigas cómo las mujeres jóvenes van construyendo su género de otras maneras, pero siguiendo también esta idea del linaje que es muy potente que implica resignificar y darles otros sentidos a las herencias culturales, políticas y sociales.

SIL: Exactamente, las prácticas ya vienen investidas de sentidos sobre el modo de entender el género, de vivirlo y habitarlo, pero es cierto que efectivamente la noción de linaje o de genealogía femenina - que no es mío, viene de teóricas europeas - tiene que ver con eso, con cómo volver a habitar y a pasar por el cuerpo experiencias generizadas que traen otras mujeres que nos precedieron, lo mismo otras contemporáneas. La genealogía ofrece la posibilidad de construir un recorrido, que nunca es previo a su relato. Por eso el relato de experiencias permite revisar cuál es el linaje en el que se inscriben mis prácticas en términos de lo que retomo, así como de lo que me separo o reinvento, o creo. De esta manera podemos observar la transformación en la experiencia vital biográfica, y su relación con las transformaciones sociales más amplias. Pensando en mi investigación actual, me interesa analizar qué reapropiaciones pueden hacer las jóvenes respecto del feminismo, que ya las ubicó en ese lugar protagónico. Porque eso también es muy fuerte para muchas, el haber sido puestas en el lugar de hacedoras de una revolución, la de las hijas. ¿Pueden habitar ese significante? ¿Cómo lo hacen? ¿En qué medida pueden ser protagonistas de una coyuntura histórica y al mismo tiempo no poder del todo serlo desde la propia vida? Están todavía tensionadas por un montón de prescripciones de género que 
no son tan fáciles de modificar y de remover como un significante que ponen otros, un hashtag que se instala sobre el efecto que las chicas provocan como sujetas políticas en el escenario más amplio del feminismo local. Entonces, me parece interesante escucharlas en el marco de una conversación, que vuelve a instalar esa dimensión de la confianza, de la enunciación más en voz baja, que no es la que hacen las chicas cuando se instalan en el Congreso a pedir la legalización del aborto, dado que allí claramente se trata de una vociferación política, de un grito plural por todas las que no pueden hablar. Ahí es un «quiero que todos me escuchen, quiero gritarlo y muestro mi enojo y mi hartazgo». Me parece, en cambio, que es en una escena más íntima donde es posible escucharlas detenidamente, donde es posible entrar de a poco, muy hasta donde cada una quiere y puede, a su propio mundo íntimo, y ver ahí cómo opera el feminismo del cual se dice que son protagonistas, cómo viven esta experiencia, cómo les queda este sayo que le han puesto, que no significa que no sean o se sientan feministas, o que no hayan protagonizado momentos de una coyuntura de transformación. Creo que, de vuelta, hay una nominación de otros hacia les jóvenes, en este caso hacia las chicas, que hoy las unifica en un universo parejo inexistente, y entiendo que es momento de abrir eso, de darle aire y ver efectivamente cómo es habitado ese lugar en el cual han sido puestas por sus acciones en la esfera pública, y cómo funciona al mismo tiempo la articulación público-privado-íntimo sobre la cual ha reflexionado tan complejamente el feminismo, en la experiencia biográfica de las distintas jóvenes. Cuáles son hoy los insumos políticos del feminismo, y de estos activismos jóvenes de género, y qué alcances reales tienen en las dinámicas de gestión de las relaciones en la vida privada, comunitaria y familiar por parte de las chicas.

CAV: ¿Actualmente estás indagando en la intimidad de las chicas en este contexto de activismos jóvenes feministas? 
$\mathrm{SE}$ : Esa es la pregunta que me estoy haciendo ahora, y en relación con las jóvenes en distintos contextos y geografías de la Argentina. Es importante considerar la diversidad del territorio, que tiene zonas de mucha pobreza, así como espacios de fuerte neofeudalismo cultural. Debemos evitar reproducir la cristalización de la escena de las chicas como baluarte del feminismo y como protagonistas de la marea verde marchando por las principales ciudades del país como única escena que las muestra y las nombra. Me interesa averiguar qué significa asumirse como feminista en distintos lugares del país, con su trama sociocultural o geopolítica específica, y, por otro lado, si no se reconocen como feministas, ¿cuál es lugar que el feminismo les otorga a estas chicas? Porque eso también es importante, en qué medida el feminismo no es necesariamente un sintagma que incluye una totalidad, sino que permite la diferencia y por ende múltiples posicionamientos en el adentro, en los bordes y más allá de él. Una cierta circulación por su campo que no implica una identidad plana o un pertenecer restrictivo, sino más bien un fluir, por supuesto, no exento de conflictos. ¿Qué pasa con todo eso? Me interesa problematizar las posibilidades concretas que tienen las chicas, en sus propias vidas, de apropiarse de esos insumos políticos, ya sea porque forman o han formado parte de activismos feministas, o porque se están socializando en un clima cultural muy distinto al de apenas 15 o 20 años atrás. ¿Por qué digo esto? Porque los datos más duros en nuestros países muestran que la violencia de género no ha disminuido, que la pandemia la ha incrementado, que todavía es muy difícil la negociación en el terreno de la sexualidad, y que correr completamente ciertos mandatos vinculados con la ideología del amor romántico es aún algo muy alejado de la realidad de muchas.

CAV: ¿Cómo surgen ahí las preguntas incómodas?

SE: Tenemos un montón de palabras que ahora nombran nuestro enojo o nuestras ganas de mostrarnos libres, deseantes. Eso está hoy disponible y es muy potente que las cosas se puedan nombrar, que no sean vergonzantes. La 
pregunta es en qué medida eso efectivamente puede escalar en los vínculos de relación, que son tan fundamentales para pensar los modos en que los sujetos jóvenes, chicos, chicas y chiques están hoy tramando sus dinámicas vinculares en comunidad, en las instituciones y en las familias. Por ejemplo, la interpelación de las chicas a sus padres: ahora se dan cuenta de que su padre es un machista y se lo puedan decir en la mesa familiar. Esto es una ruptura cultural muy importante, como igualmente importante es que puedan revisar el modo y las posibilidades que tienen de cambiar las condiciones de la elección de pareja, de la relación entre mujeres, de pensar y gestionar la autonomía del cuerpo. O sea, el feminismo da un marco y un lugar donde alojarse, pero al mismo tiempo allá «adentro» hay baldosas muy distintas donde hacer pie. Me interesa ver estas oscilaciones, porque todas las veces que los análisis sobre juventud, género, clase y política se estabilizan en lugares cómodos $\mathrm{o}$ encuentran la palabra que nombra todo, ahí digo «hay que irnos de aquí». Ese es el momento de fundar sospechas, hacer nuevas preguntas, mirar mejor y revisarlo todo.

CAV: Estaba pensando en toda esta crítica, que mencionabas, al amor romántico, pero ¿con que lo reemplazamos? ¿Cómo nos relacionamos de otras maneras? Revisando a autoras como bell hooks (2021) respecto a cómo pensar y hablar del amor, pero no es dejar el amor de lado, sino que transformar radicalmente nuestras comprensiones sobre el amor y sobre las relaciones. En ningún caso es renunciar al amor, porque a veces queda instalada esa idea y también esto de «soy sola, yo puedo todo sola y no necesito a nadie», que es muy individualista. ¿Cómo ves esto en las/os jóvenes?

SE: Sí, además está esta cuestión del amor o de la sexo-afectividad, tema muy recurrente en el diálogo con les jóvenes. Aquí también se nota una operatoria diferencial en términos de clase sobre algunos tópicos más que otros. Por ejemplo, cuando se empieza a hablar de cuidados y autonomía corporal, aparece una distancia muy grande entre las chicas comunes de sectores empobrecidos y 
las empoderadas y activistas de clase media, que no piensan en la maternidad como un proyecto de realización personal, o que en todo caso, si tienen una relación de deseo con eso, confían en que van a poder gestionar ese deseo a partir de planificar un embarazo, a la vez que saben que, si esa fuera su voluntad en un cierto momento, la posibilidad de interrumpirlo hoy está disponible legalmente. Muy distinto de lo que ocurre en las realidades de numerosas chicas de sectores populares, donde la condiciones pueden ser otras con relación a todo, desde la edad de iniciación sexual hasta cómo se traman los vínculos sexo-afectivos y cuáles son los márgenes de acción con que cuentan, en sus relaciones personales y en las instituciones a donde asisten, de enunciar su deseo y ser escuchadas. De todos modos, respecto del amor, es notorio cómo hay un uso extendido del vocabulario de derechos que dan las leyes o las políticas públicas de género desarrolladas en los últimos años en el país, sobre todo entre las jóvenes urbanas de clase media. Está muy instalada la idea de haberse empoderado, y desde allí demandan relaciones sexo-afectivas igualitarias y están prontas a denunciar abusos. Sin embargo, a la hora de narrar cómo viven alguna experiencia amorosa concreta, no son pocas las que zozobran y translucen cierta angustia, en medio de las tensiones que se producen entre el deseo de amor y la creciente protocolozación de los lazos eróticos y afectivos.

CAV: Lo que tu decías sobre volver a estas preguntas, como por ejemplo que lo personal es político y volver a mirar cómo todas estas trasformaciones impactan a las/os jóvenes en sus relaciones sexo-afectivas.

SE: Claro, porque es una pregunta, fíjate, Carolina, que la trae la propia coyuntura. Como nunca antes, por lo menos en la Argentina, se publican libros sobre amor, sobre sexo- afectividad, sobre poliamor; como nunca antes el periodismo, los medios, las redes y las propias chicas que entrevistamos hablan de amor, no porque antes no se hablara, sino porque ahora se lo habla y tematiza en una clave vinculada con los activismos de género. Tampoco puedo 
decir que todo tiene que ver con el feminismo, porque efectivamente su narrativa no llega a todos lados del mismo modo, ni convence a todos los sujetos, ni mucho menos. Pero sí decir que cierto repertorio representacional del feminismo hoy permea la discursividad social más amplia y da marco a expresiones de las chicas, como «no es no», «yo te creo, hermana», o «ni una menos», al mismo tiempo que habilita la ampliación del arco de prácticas que pueden ser consideradas como violentas. Esa inteligibilidad de la experiencia, basada en el uso de estas significaciones y nuevas herramientas nominativas, produce un sujeto joven, digo chicas o chicos, con mucha competencia para la interpretación racionalizada de lo que ocurre en sus vidas de relación. Entonces observamos distintas situaciones. Por ejemplo, la calificación de cierta práctica del compañero como «machirula» puede conducir a la acción pública de la denuncia: «vamos a tacharlo», «no vamos a soportar este tipo de cosas», pero también a la evaluación in toto de ese varón como «machirulo». Hoy, las chicas cuentan con nuevas y más palabras que les permiten nombrar lo que sienten o les pasa, a la vez que su propia enunciación está enmarcada en una escena donde ellas encarnarían a un sujeto políticamente potente. Lo que me interesa señalar es que estas circunstancias luego son vividas de maneras múltiples, al interior de las estructuras familiares, de las relaciones íntimas, de las escuelas, de las universidades, porque esas instituciones tienen códigos que a su vez vienen tramados desde su propia historia. Si seguimos etnográficamente el itinerario de distintas chicas y chicos, pues circulan por una familia, tienen un novio o una novia o lo que fuere, militan en la escuela, van a una marcha... Todos esos recorridos no son iguales ni lineales en su propia vida. De allí que esos insumos políticos que proveen el discurso feminista y las prácticas activistas de les mismes jóvenes se reconfiguran en cada uno de esos espacios. La complejidad de estas dinámicas es lo que me interesa analizar. 


\section{LA CONVERSACIÓN Y LA ESCRITURA RESPETUOSA, O CÓMO NO TAPAR LAS VOCES}

CAV: Ahora, sobre las metodologías que has utilizado en tus investigaciones, revisando algunos de tus trabajos sobre el cuerpo, la emocionalidad y los sentidos disruptivos, recurres a la etnografía como modo de indagatoria. En este sentido, ¿cuáles han sido tus metodologías y cómo han ido variando? ¿Cómo ir investigando todo esto que se va moviendo y transformando tan rápido? La pandemia cambió también todas estas formas, ¿cómo has pensado este acercamiento a los sujetos y las sujetas que estudias? Señalabas esto de la cultura del cuarto, que implicaba también otra forma de acercarse y ahora, ¿cómo estás planteando esta investigación de estudiar la intimidad? Pensando que es complejo estudiar la intimidad de las chicas, de sus relaciones en distintos ámbitos, ¿cómo acercarse metodológicamente en estas investigaciones?

SE: A ver, podría decir que en términos generales, siempre he navegado las aguas de la socioantropología, con metodologías que han sido principalmente cualitativas y basadas en el acompañamiento por los circuitos por los que se mueven las jóvenes. Creo que eso permite en parte dar cuenta de la dinámica de los sujetos en el marco de sus condiciones de existencia. Pero también es cierto que al trabajar con estos cruces, donde tan fuertemente me ha importado la pregunta por el género y la sexualidad, también las metodologías feministas han alimentado mi recorrido. En general, soy poco ortodoxa para pensar cuál es la metodología adecuada para cada momento de una investigación. Puedo, claro, construir un protocolo metodológico correcto y pertinente para la formulación de un proyecto, pero soy muy consciente de que puede cambiar de un momento para el otro, conforme las prácticas sociales bajo estudio se van desplegando en condiciones siempre situadas y específicas. Por eso es clave tener presente que ninguna metodología es completa y exhaustiva, y que — por lo menos pisando terrenos etnográficos - la combinación de técnicas nos permite en general asir 
más complejamente el sentido que los sujetos les otorgan a sus prácticas. Puedo decir que sí me han interesado mucho dos cosas. Por un lado, reflexionar sobre el momento de la entrevista, que es una herramienta muy potente y que cuenta con una enorme legitimidad entre las metodologías cualitativas empleadas en las ciencias sociales. Me interesa pensar cómo evitar todo elemento de colonización de la palabra: ¿cómo lograr más auténticamente, más genuinamente, una escucha abierta sobre temas sensibles, como los asociados a las desigualdades de género, o la vida sexual de las personas? Porque la pregunta puede echar a rodar una invitación convocante para despertar la narración en primera persona, o ser sistemáticamente rechazada por parte del sujeto entrevistado si lo vulnera o lo deja en un lugar desconocido. Me acuerdo de un texto que escribí hace muchos años, creo que en el 2014, en el que relaté una situación de campo. Hacía meses que visitaba un Hogar de Tránsito (así se denominaban por entonces) en el que vivían temporariamente varios chicos y chicas, en su mayoría pobres, por derivación de la Justicia. Un día llegué y le conté al grupo sobre la investigación que estaba realizando y mi interés por conversar con ellos y ellas. Por toda respuesta a mi consulta de si aceptaban ser entrevistados y entrevistadas, un pibe me interpeló «¿y qué vas a hacer con lo que nos preguntes?». Ahí comprendí parte de los efectos que podía tener una entrevista, por caso para estos chicos y chicas cuyo destino dependía en gran parte de las respuestas que dieran a las psicólogas y asistentes sociales sobre sus acciones, de cara a elaboración de informes que les profesionales luego elevaban a los Juzgados. En esa oportunidad contacté con la dimensión extractiva que puede llegar a tener, también, la entrevista en tanto técnica de recolección de datos, y no porque haya una voluntad maquiavélica detrás, sino por el efecto de cómo nuestra autoridad para interrogar parece funcionar automáticamente, sin mayor justificación que ese conjunto de párrafos que solemos dedicarle al apartado metodológico en la redacción de un proyecto. Tensionando esto último, el feminismo me enseñó a prestar aún más atención a las resonancias que pueden generar nuestras preguntas en un entrevistado o 
entrevistada, a las fibras que puede conmover, y que va más allá de la adecuación o inadecuación de su formulación precisa. Por todo esto, en principio, más que una entrevista busco proponer una conversación, porque en ella, el lugar de quien conduce y lo dicho pueden cambiar. Por otro lado, otro momento de mucha reflexión para mí es la escritura, porque en ella está el riesgo de que aún completamente relevados los datos con técnicas adecuadas y respetuosas, aun así, la escritura pueda «traicionarlos» (también comillas). Por ejemplo, cuando termina usando el relato de una experiencia como ilustración de lo que el o la analista quiere decir, para autoafirmarse en su lugar de autoridad y de saber, en vez de permitir ser transformado/a o interpelado/a por esas narraciones. Para mí, la escritura es una manera de elaborar el conocimiento que conlleva una enorme responsabilidad. En ella los conceptos tienen que servir para abrir y complejizar la interpretación y no para volver a encapsularla. Disponemos de unas categorías increíbles, productivas, muy seductoras también, en lo personal me gustan muchos conceptos de la teoría feminista para pensar y revisar mi trabajo. El punto es qué hago con eso, qué efectivamente puedo decir de las chicas que estudio en cada momento, qué puedo decir que no sea que esos sujetos de investigación están cumpliendo un rol para el concepto y no el concepto permitiéndome atravesar una experiencia biográfica convertida en dato, finalmente. Entonces digo, la metodología es una construcción en permanente movimiento y requiere de un trabajo continuo de autorreflexividad por parte del o la investigadora. La pandemia expuso esto mismo de un modo impactante. Luego, también hay que pensar si no hay otros lenguajes, otros modos de registrar el relato de la experiencia de los sujetos, otras formas de aprehender su universo de sentidos. Me pregunto si todo está soportado en la palabra, si el registro de la imagen, de las disposiciones del cuerpo o de los silencios no son también otras formas valiosas de acercarnos. También creo que es mejor avanzar más intuitivamente en el sentido de ir viendo, ir sondeando lo que efectivamente traen esas metodologías, para revisarlas, para abandonarlas si es necesario, para reponer otras. Mi mirada está 
siempre más próxima a la socioantropología, no solo porque hice un doctorado en antropología, sino porque su propuesta metodológica me ha nutrido enormemente. El estar allí, acompañar en terreno el recorrido de las jóvenes, traer información contextual y de la enunciación, que es tan importante. En mis trabajos también aparecen el registro documental y las estadísticas, siempre en diálogo con las condiciones de formulación de mis preguntas. De hecho, creo más en la mirada de articulación con los contextos que en la garantía de los números.

CAV: Me parece súper interesante lo que dices porque justamente estoy en esa misma disyuntiva que comentas respecto de evitar la colonización de la palabra, pero a la vez no renunciar a la interpretación de lo que dicen las y los sujetos. Esa compleja línea de no «traicionarlos», de no romper esta confianza que se dio en la conversación, como lo señalabas. Pero cómo damos ese salto interpretativo sin traicionar, ¿cómo lo manejas en este proceso de escritura? ¿Cómo desarrollar una escritura respetuosa? Cuestión de la que se suele hablar poco.

SE: Lo primero es asumir este lugar hermenéutico que nos toca, interpretando interpretaciones que a su vez están basadas en otras interpretaciones, ahí hay una dimensión coral muy sugerente. Por supuesto que la propia interpretación implica una responsabilidad, hay que jugársela, lo cual también habla de un compromiso, que me parece importantísimo explicitar. Ahora bien, la explicitación de las condiciones desde las cuales decimos sobre lo social no nos eximen de la responsabilidad de lo que hacemos al decir e interpretar, no es solo un lugar transparente per se. Tampoco la explicitación de nuestras diferencias garantiza un análisis libre de prejuicios, «soy mujer, heterosexual, blanca, un poco rubia», que sé yo, «educada, instruida». Exhibir las propias «etiquetas» no tiene nada que ver con el compromiso epistemológico y político que deberíamos asumir respecto del trabajo que hacemos. Digo, no funcionan como garantía ni de objetividad ni de anticipación. No es que ya ubicada desde 
cierto lugar ante el otro puedo entonces avanzar despreocupadamente sobre los impactos de ese posicionamiento. La autoasignación de un lugar de enunciación se modificada en el encuentro mismo con el otro, en la medida en que el otro puede leer ese conjunto de clivajes identitarios de cualquier otra manera distinta a la mía, con otra escala jerárquica, desde otras acentuaciones de la diferencia. Entonces, de nuevo, es un trabajo hermenéutico. La epistemología feminista tiene una vuelta interesante ahí, pues produce todo el tiempo una autorreflexibilidad que trabaja también en relación con la automirada, con el registro del conocimiento situado y encarnado. Esta dimensión visceral del conocimiento - lo que digo y escucho me pasa por y en el cuerpo - va de la mano de asumir que, en una conversación, las palabras que digo son también el producto del encuentro con el otro, con lo que me dijo y de lo que me produce lo dicho y su decir, sus resonancias. A su vez, también está lo que habita en mí, y ahí hay una invitación en la escritura a tomar un lugar, a tomar una palabra. Quienes hacemos investigación tenemos una palabra pública, por eso tenemos responsabilidad sobre la construcción de esa voz, pero sabiendo (por lo menos a mí me interesa tenerlo presente) que nuestra palabra también es movilizadora, es decir, modula las experiencias de les otres y de los lugares desde los que son leídos. Siempre me parece más interesante correrse del lugar de experto o de experta, y ubicarse en el lugar de alguien que se hizo preguntas, que es algo bien distinto. Por eso reniego de las invitaciones a decir generalidades sobre el conjunto de les jóvenes en todo el país. No lo digo por el detalle versus la generalización, lo digo en términos de pretender, asumir o arrogarse el lugar de hablar por un conjunto, siendo a su vez que ya sabemos que es absolutamente heterogéneo. Esa tensión tiene que estar abierta y creo que tiene que formar parte de nuestro trabajo. No creo que haya un lugar, un modo, un dispositivo, un saber, que pueda suturar esa tensión y relajarnos. No es como «bueno, ya está, ya encontré el lugar más cómodo». El nuestro es siempre un lugar de incomodidad, en la medida que está tensionado, está tironeado, pero sí me parece que la reflexividad y la autorreflexividad operan en el sentido de no 
perder la dimensión relacional de quienes hablamos en una investigación, ni suspender el registro sensible de que la voz que conduce finalmente la escritura no sea una voz que tape a las otras.

\section{EL CAMPO DE ESTUDIOS EN LA ACTUALIDAD: LA CLAVE GENERACIONAL PARA LA COMPRENSIÓN DE LA ÉPOCA}

CAV: Para cerrar, ¿cómo ves el campo las juventudes en la actualidad? ¿Cómo lo proyectas en un contexto de mayor diversidad de temas y preguntas?

SE: Respecto del momento presente me parece imprescindible sumarle la pregunta por los impactos de esta pandemia, tanto en los modos de hacer investigación y de hacernos preguntas, sobre los y las jóvenes Es muy pronto para saberlo, pero creo que es muy importante no entender esta coyuntura como episódica. Por el contrario, considero que nos ha impactado a todes de una manera muy fuerte e irreversible. Claro que no es lo mismo estar en marzo del 2020 que estar ahora, se trata de una coyuntura que ha tenido distintas etapas e intensidades y que sigue cambiando. Me refiero a reflexionar sobre los impactos materiales y subjetivos producidos por la experiencia del distanciamiento y del encierro en las nuevas generaciones, el modo en que debimos repensarnos en una coyuntura donde la voluntad personal se ponía en suspenso para inscribirse en una voluntad general que tenía unos criterios y unas metas propios. Reponer también una reflexión sobre la experiencia visceral de la enfermedad, de la muerte próxima de otros, de la generalización de un vocabulario teñido de esos elementos, de la angustia como sentimiento subyacente a todo lo ocurrido, en una sociedad que en general niega la zozobra, que rechaza la angustia, que niega el temor como una experiencia humana constitutiva junto con otras emociones. Creo que esta coyuntura trajo algo de esa emocionalidad negada y tan despreciada, pues se considera corrosiva de la constitución del yo. Algo de todo esto es bien interesante de analizar en 
términos generacionales. No tengo idea qué formas tendrá lo que venga después de esta pandemia, qué colores ni qué texturas ni qué lenguaje asumirá, ni en qué tiempos o con qué impulso. Quizás el arte lo pueda captar anticipadamente con mayor agudeza. Por supuesto hay persistencias que incluso trascienden pandemias, pero me parece que esta coyuntura local y global es una condición a incluir - yo diría con mucho respeto- en nuestros trabajos futuros con relación a cómo nos ha modificado como investigadores e investigadoras, y en las preguntas que nos vayamos a hacer de aquí en más.

CAV: Porque también la intimidad se ha redefinido o cambiado en este tiempo.

SE: Lo que ha cambiado son las condiciones en que ciertas prácticas se producen y las condiciones en y desde las cuales nos interrogamos sobre esas prácticas. Estas nuevas condiciones son materiales de análisis, no meramente un «telón de fondo» ni aquello que arma el escenario que miro. El desafío es pensar la pandemia no como una exterioridad que se nos impuso sino como algo (insisto) que nos ha atravesado a todes, que hemos co-construido tanto como resistido, y me parece interesantísimo leer estas condiciones en una clave generacional, y en una clave epocal. Quizás para ello tengamos que inventar otras metodologías, otros conceptos para abordar lo nuevo que haya traído, que haya dejado, o que haya reinventado esta pandemia, no solo a nivel local sino en su dimensión planetaria. Hay mucho que revisar, creo que es un desafío que estamos sin poder ver con claridad todavía, porque lo estamos atravesando, pero también es una oportunidad. Pienso que las transformaciones son oportunidades para las ciencias sociales, para revisarse, para repensarse e inventarse nuevamente. Ojalá que desde el campo de los estudios de juventudes podamos aprovechar esta invitación histórica.

ENVIADO: 28 DE JULIO DE 2021 ACEPTADO: 7 DE AGOSTO DE 2021 


\section{BIBLIOGRAFÍA}

ELIZALDE, S. (2006). El androcentrismo en los estudios de juventud: efectos ideológicos y aperturas posibles. Última Década, 14(25). https://doi.org/10.4067/S0718-22362006000200005

. (2018). Contextos que hablan. Revisiones del vínculo género/juventud: del caso María Soledad al \#niunamenos. Última Década, 26(50), 157-179. https://doi.org/10.4067/S0718-22362018000300157

Elizalde, S. y FelitTi, K. (2015). «Vení a sacar a la perra que hay en vos»: Pedagogías de la seducción, mercado y nuevos retos para los feminismos. Rev. Interdiscip. Estud. Género Col. Méx., 1(2), 3-32.

HOOKS, B. (2021). Todo sobre el amor. Paidós. 